\title{
Delivering on the e-learning promise: A case for a learning environment that enables Collaborative Online Problem Solving (COPS)
}

\author{
Sylvia Lauretta Edwards, Jason Watson \\ Faculty of Information Technology \\ Queensland University of Technology, Australia \\ s.edwards@qut.edu.a,ja.watson@qut.edu.au , \\ Ann Farrell \\ Faculty of Education \\ Queensland University of Technology, Australia \\ a.farrell@qut.edu.au \\ Robyn Nash \\ Faculty of Health \\ Queensland University of Technology, Australia \\ r.nash@qut.edu.au
}

\begin{abstract}
Research spanning the last thirty years confirms that people learn better by active enquiry, collaboration and experimental problem solving than by passive reception and acceptance of information. Empirical evidence, as well as the pressing demands of pervasive social and technological change, requires learning and teaching approaches that combine problem-centred learning and collaborative learning, and open up possibilities for equitable participation in real-world learning. This paper mounts a theoretical and pedagogical case for such an approach by examining the developmental work being conducted in this area at Queensland University of Technology (QUT). It argues for a collaborative online problem solving environment (known colloquially as COPS) that will combine the problem-centred and collaborative dimensions of learning. The developmental work of COPS seeks to go beyond current online learning and teaching resources offered by most learning management systems, to provide a framework and system to create and deploy environments where teams of student learners can collaborate, engage, grapple with and seek to make sense of authentic problems within an online environment. It seeks to do so by creating problem-centred 'learning designs' that can be integrated with face to face teaching to bridge the gap between the classroom and real world experience.
\end{abstract}

Keywords

e-learning, pedagogy, collaborative, problem solving 


\section{Introduction}

E-learning has been part of the teaching and learning lexicon of universities for over a decade and the promises of e-learning have been a ubiquitous feature of higher education initiatives in both Australia and elsewhere. The rhetoric and practice around e-learning (known also as online learning) are well attested (Carr, 2001; Rosenberg, 2001; Svetcov, 2000; Vrasidas, 2004; Yam, 2004). Current online learning environments ostensibly deliver gains in terms of mass storage of information, yet fall short in optimising positive student engagement. Research confirms that meaningful student learning requires learning environments and learning experiences that are relevant to students' lives and to the worlds which they inhabit. It is arguable that learning experiences should be co-constructed, goal-directed and authentic, and with real possibilities for collaborative problem-solving (Jonassen, Howland, Moore, \& Marra, 2003).

Over thirty years ago, Bruner (1973) contended that people learn more effectively by active enquiry, experimentation and collaboration than by passive acceptance of content. While this seminal work continues to be corroborated by more current empirical evidence (REFS), ironically, there is a technological lag in the types of e-learning resources that best support this approach. This lag, therefore, calls for the innovative application of both pedagogical and technical resources, within an online environment, capable of advancing collaborative student learning. One such innovation is the work around the Collaborative Online Problem Solving environments (COPS) being conducted with undergraduate students, across three faculties, at QUT.

The goal of COPS is to further improve student learning by integrating face-to-face teaching methods with collaborative, problem-centred online learning environments. This requires the application of sound pedagogical approaches involving active learning (Phillips, 2005), collaborative learning (Kagan, 1994), constructive learning (Kolb, 1984; Laurillard, 2002), meaningful learning (Jonassen, Howland, Moore, \& Marra, 2003; Zenger \& Uehlein, 2001), reflective learning (Schön, 1991) and problem-based learning (Wood, 2003). Each of these elements informs the design of an online learning environment (Oliver \& Herrington, 2001). COPS stands to provide students with online learning opportunities whereby they explore problem scenarios, experiment, practise and reflect. In so doing, it incorporates a system of dynamic branching whereby the learners' decisions are central to their learning, thus increasing students' ownership of their learning. COPS also stands to enable the university teachers to develop clearer understandings of students' teamwork and problem solving, and the learning/teaching strategies that are the most effective in assisting students to improve their skill bases.

COPS is being developed at a meta level: creating an authoring tool suitable for multi domains, where lecturers can use this tool to develop their own COPS learning designs within their discipline, and to explore how learning designs can be reused. This aspect is unique, as learning management systems, characteristically, do not have this type of inbuilt support. In addition, where possible, we will build new functionality as reusable components. Hence, components that support new features such as role playing, dynamic branching, and authoring will be open for reuse. This paper further explains the teaching and learning philosophy behind COPS and our approach to developing this new online tool. 


\section{Context}

I hear and I forget. I see and I remember. I do and I understand.

(Lao Tsu, Chinese Philosopher, 6th Century B.C.)

Seminal work, such as that of Bruner (1973) attests that people learn more effectively by active rather than passive means. Within a corpus of evidence, learning through observation (listening, watching or reading) is seen to be not as effective as actually performing an action and reflecting upon its consequences (Jonassen, Howland, Moore, \& Marra, 2003; Schön, 1991; Wankat \& Oreovicz, 1993; Wood, 2003). So too, students engaging in co-construction of their own knowledge through an action-reflection cycle (rather than obtaining knowledge directly from a teacher) leads to a deeper level of knowledge and skill (Holmboe \& Scott, 2005; Nelson, 1999; Rust, O’Donovan \& Price, 2005; Vygotsky, 1978).

The pervasiveness of the Internet means that learning institutions can provide mass access in costeffective ways. Whilst e-learning promises reduced costs and increased effectiveness, accessibility and flexibility, there remain persistent short comings. In many cases there has been a focus on technology and content as opposed to learning effectiveness (Yam, 2004). Key issues include online learners' perception of not feeling engaged, finding the content boring, feeling isolated, not understanding the context, having insufficient control, and students not feeling motivated (Rosenberg, 2001). Drop-out rates in e-learning have been quoted to be as high as $35 \%$ (Svetcov, 2000). This scenario is not surprising as many learning organisations have been found to use online facilities as reservoirs for traditional materials (Vrasidas, 2004; Yam, 2004).

Jonassen, Howland, Moore, and Marra (2003) argue for five factors required for learning to be 'meaningful':

- $\quad$ Active learning - observing or manipulating the environment

- Constructive learning — creating meaning from experience

- Intentional learning - goal directed

- $\quad$ Authentic learning - keeping the learning in context

- Cooperative learning — being able to collaborate with other learners.

Recognition of these factors has, in part, propelled a shift of focus in online learning from learning content to learning experience. For example, Harper (2003) examined how contemporary theories of learning can be applied in an online environment. Traditionally, e-learning has focused on cognitive models of learning that are consistent with more structurally-based approaches to learning content.

Contemporary theories such as constructivism (Caprio, 1994; Dewey, 1938; Jonassen, 1991; Piaget \& Inhelder, 1969; Vygotsky, 1962) are not readily accommodated in traditional learning management systems where structure is a requisite part of the learning design. Constructivist approaches are more readily facilitated in a collaborative environment where learners can validate their perspectives through social negotiation and interaction with an authentic task. Importantly, Jonassen (1991) states that a constructivist approach is particularly appropriate as much of what needs to be learned involves advanced knowledge in ill-structured domains. 
Laurillard (2002) describes how the complex process of learning can be considered as a 'conversation' within a learning framework. This framework (Figure 1) is intended to be applicable to a range of academic learning situations and employs the following four strategies:

1. it must operate as an iterative dialogue

2. it must be discursive, adaptive, interactive and reflective

3. it must operate at the level of descriptions of the topic

4. it must operate at the level of actions within related tasks.

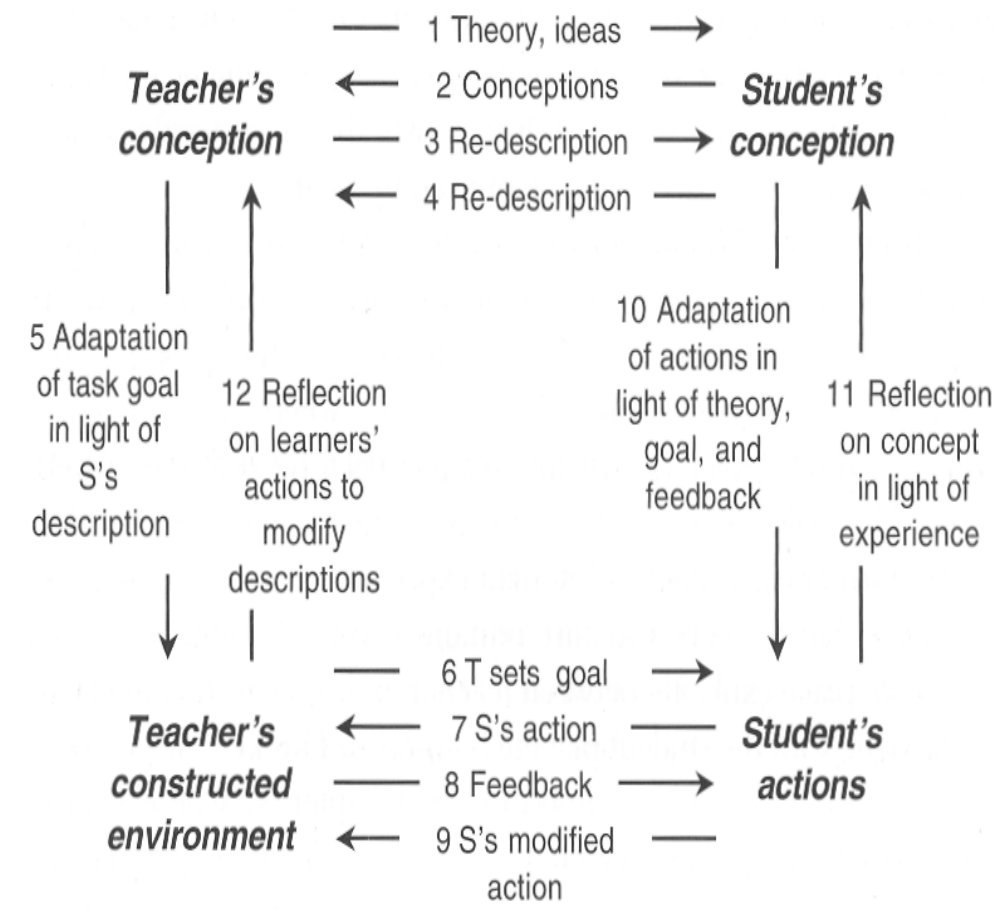

Figure 1: Laurillard's conversational framework (Laurillard 2002, p. 87)

The iterative approach in Figure 1 is based upon an extended version of Kolb's (1984) model of experiential learning: a continuous cycle of conceptualisation, experimentation, experience and reflection. Both of these models (Laurillard's and Kolb's) define learning as a cycle and endorse the need for student reflection within that cycle. They also emphasise the need for an 'environment' or 'problem' with which learners can experiment and receive feedback; an environment where learners are active, grappling, seeking to make sense, experiencing, forming assumptions, testing and creating meaning from their experience. Problem-centred learning is a well known strategy for assisting deeper, critical active learning strategies and thus fostering the development of higher quality learning outcomes (Ramsden, 1992).

Laurillard's framework seeks to describe the dialogue that needs to take place for learning to occur. However, it does not refer to the dialogue between learners (that is, where learners can profit from each other's different perspectives and strengths). Learner collaboration, where learners with aligned goals help each other towards some common objective, can enhance a constructivist learning cycle by providing an additional channel for validation and feedback (Jonassen, 1991). Located in sociocultural theory, collaborative learning emphasises the importance of social interaction in the learning process (Vygotsky, 1978). Collaborative learning can also help to maintain an authentic context, allowing learners to understand the importance of working well together for the good of the whole. Authentic learning is often collaborative, providing students the opportunity to reflect and examine the task from different perspectives (Herrington, Oliver, \& Reeves, 2003). But as these tasks may also be ill-defined and/or relatively complex, the students are expected to define the tasks and sub-tasks needed to complete the activity. 
Herrington, Oliver \& Reeves (2003) contend that for online authentic tasks to be effective as learning tools, then during the first few weeks of immersion into the learning environment students must be supported because 'isolation can be a mitigating factor against successful engagement with the course.' (p. 68). Their work supports the notion that the dialogue between the learners may be necessary to achieve success in e-learning.

This should not be surprising, as industry uses cooperative incentive structures which create a situation where the only way team or group members can attain their own personal goals is if the group is successful. Therefore, to meet their personal goals, group members must both help their group mates to do whatever helps the group to succeed, and, perhaps even more importantly, to encourage their group mates to exert maximum efforts (Slavin, 1995a; 1995b). Collaborative problem solving comprises a set of skills that are considered necessary for success in today's world

(O’Neil, Chuang, \& Chung, 2003). Importantly, the development of such skills requires a learning/teaching approach that combines both problem-centred learning and collaborative or cooperative learning (Nelson, 1999).

Collaborative learning environments provide a means to create more engaging and dynamic instructional settings (Kagan, 1994), and research has demonstrated the educational advantages that can be derived from such environments (Bruffe, 1999; Jonassen, 1995; Qin, Johnson \& Johnson, 1995; Slavin, 1995a; 1995b). Collaborative problem solving emphasises cooperation in the context of a 'carefully constructed scenario' (Edens, 2000; Major \& Palmer, 2001) and is underpinned by pedagogical values that include the creation of learner-centred learning environments, student ownership of the learning experiences, analysis of learning content and exploration from multiple perspectives, and the importance of the social context for learning (Nelson, 1999). There are, therefore, important educational imperatives to employ collaborative problem solving as a constructivist learning strategy for students.

\section{Introducing the COPS environment}

The development described in this paper is the construction of a framework and system to create and deploy environments where learners collaborate, engage, grapple with and seek to make sense of authentic problems whilst online. Tentatively titled Collaborative Online Problem Solving (COPS) (2005), this new environment stands to enable teaching staff to create reusable problemcentred 'learning designs' that can be integrated with face-to-face teaching in order to bridge the gap between the classroom and real world experience. COPS specifically addresses the teaching and learning priorities of work-integrated learning via relevant authentic problems, the generic capabilities of problem-solving and teamwork, and transition from university to the workplace.

\section{COPS development aims}

Specifically the aims of this development are to:

- $\quad$ provide learners with a meaningful, contextualised opportunities for learning in an online environment

- $\quad$ develop an online environment where teams of learners can undertake roles and work to solve authentic problems that can best be solved by successful collaboration; emphasising communication and collaboration rather than individual activity 
- $\quad$ encourage students to form a personal stake in the learning process through simulation, role playing and having fun

- $\quad$ provide opportunities for students to make mistakes in a non-threatening environment

- $\quad$ develop a range of reusable COPS learning designs (templates) to provide an affordable, consistent, high quality learning experience based on engagement and active learning

- develop strategies to assist teachers in the design and evaluation of their 'problem' environments and to assist with integration with face-to-face teaching.

The intention is to allow teachers to develop learning environments that encourage collaboration rather than individual activity. This, in turn, should provide students with online learning opportunities whereby they explore problem scenarios, experiment, practise and reflect. In so doing, COPS will incorporate a system of dynamic branching whereby the learners' decisions are central to their learning, thus increasing student ownership of their learning.

\section{Proof of concept}

This development stems from an earlier QUT, Faculty of Information Technology (FIT) proof of concept model (CITI, 2004) developed to support collaborative and story/problem-centred learning (see Figures 3 and 5). This proof of concept has formed the basis of the initial design work in this development. There are two workflows associated with this model. One is a problem scenario workflow and the other a pedagogical workflow.

\section{Problem scenario workflow}

The problem scenario workflow represents the problem which is imbedded into a COPS scenario (Figure 1). In the workflow figure below we see that this problem has one starting state, a series of intermediate states, and three possible endings to the problem. It could be conceived of as choosing one's own adventure, a device used in young adult literature, where the reader makes choices from a range of possible alternatives until they reach the end of the adventure. It is important to note that the amount of branching is entirely at the teacher's discretion; they may have as many, or as few, decisions as suits their problem.

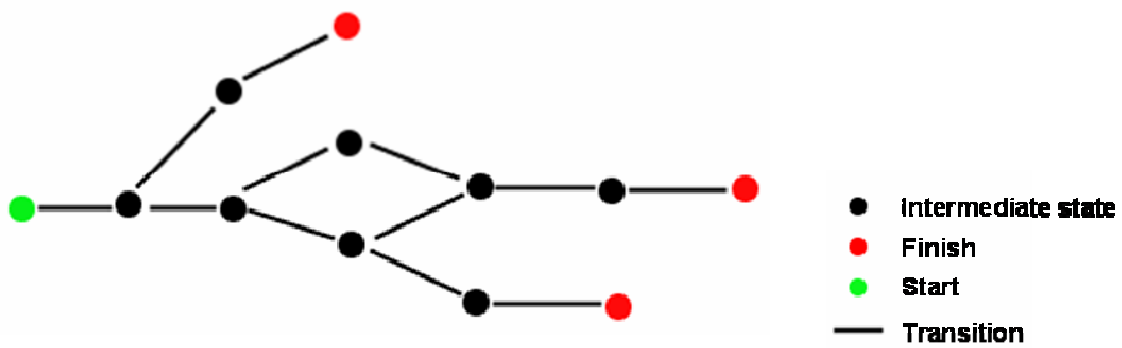

Figure 1: Problem scenario workflow 
The size of the teams will be at the teacher's discretion. In the COPS case, a student team traverses the problem workflow by making a decision at each stage of the problem. This decision triggers a transition from one state of the problem to another. It is also at the teacher's discretion whether or not the students undertake roles which are unique to each person in the team. For example, one problem may involve a team of students role playing as 'high school teachers' who each teach the same 'high school student' in different classes. One or more of the role playing teachers notice a problem with the 'high school student' and the team then discuss their options so that a team decision can be made. Decision point triggers can be activated based upon one or more actions from one or more role players, or from random events, or even from time outs (a specified period of elapsed time passes so the problem progresses to the next stage). Teaching staff can 'force' consequences on the team for non-collaboration by setting up a transition so that it requires more than one role player to complete an action before the transition to the next stage can take place. The team is primed that they have to achieve a specific goal, and that they are expected to traverse the problem together until they reach an outcome that they believe achieves that goal. However, it should be noted that there may not be a single best outcome for problem resolution. For example, in some ethical situations there may be no black or white answer - it is the journey that is important.

At every intermediate state students are provided with a description of the requirements, and they can access numerous resources that facilitate investigation, decision making, outcome prediction, and personal and team reflections. These resources are added by teaching staff and they may contain information specific to each role player and to each state of the problem workflow. This will increase the authenticity of the problem, and facilitate collaboration using the 'Jigsaw' approach: where no individual student has all the information necessary to act appropriately (Aronson, Blaney, Sikes, Stephan, \& Snapp, 1978). It is also possible to design a learning environment so that students from different year levels interact together, so that students in final years may act as mentors for students in lower year levels, offering advice as required. The resulting COPS environment, therefore, encourages constructive collaboration by the students to explore problem scenarios, experiment, practice and reflect.

In the proof of concept model, the problem workflow was set up and populated with content using the problem workflow authoring interface (Figure 3). This interface guides the teaching staff in their establishing of their problem scenario. It is intended that this will be further enhanced in the final version of COPS.

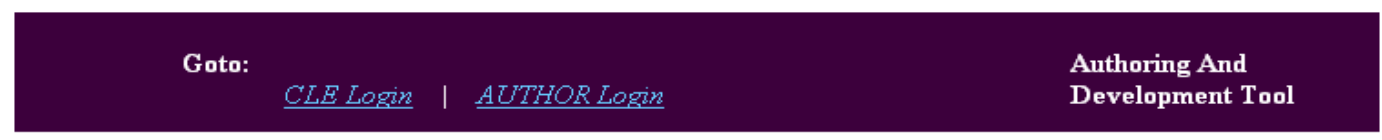

Edit States And Transfers Options

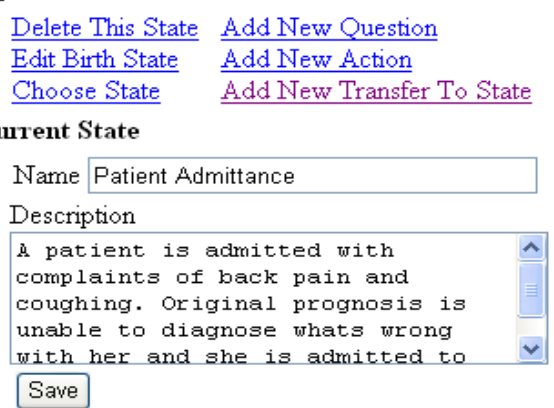

$$
\text { Incoming States }
$$

Further Agitation

\begin{tabular}{ll}
\hline Outgoing States & \\
Further Agitation Edit State Transfer & \\
\hline Success Edit State Transfer & \\
\hline Patient Death Edit State Transfer & \\
\hline & \\
\hline$\downarrow$ Questions & \\
\hline$\downarrow$ Actions & \\
\hline$\downarrow$ Images & \\
\hline
\end{tabular}

\section{Finish}

Figure 3: Proof of concept problem authoring interface (CITI, 2004) 
To support student learning COPS integrates Kolb's pedagogical cycle with the problem workflow (Figure 4) using role play. This cycle is consistent with a constructivist approach and involves students experimenting, experiencing, forming assumptions, testing, and creating meaning from experience. At any time during the life of the 'problem', rudimentary elements which support students in each of the steps in Figure 4 can be created and therefore seen displayed in the student interface (Figure 5), for example, the top tabs showing investigate, reflect, act, and side links to the journal, reflection and collaborative areas. The collaborative area provides opportunities for interaction. If the teacher chooses to design the problem so that collaboration must occur before a decision can be reached, then it is possible to ensure that students are encouraged to interact with their team mates throughout the problem, thereby helping to reduce the likelihood of isolation during the learning process (Herrington, Oliver, \& Reeves, 2003).

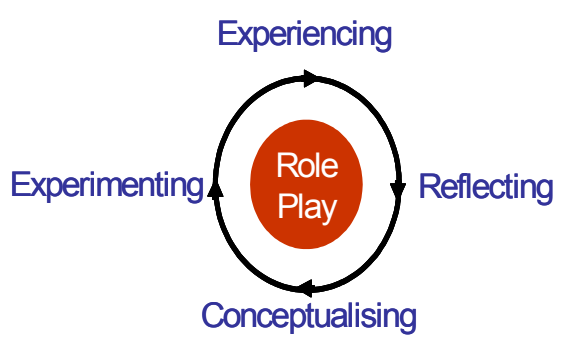

Figure 4: Our use of Kolb's (1984) pedagogical cycle

\section{The student interface}

The objective of the student interface (Figure 5) is to present the problem scenario to each role player with any relevant content for their role at that particular stage of the problem. In addition, the interface must explicitly drive the student through the pedagogical cycle in Figure 4 . In this cycle the system separates the investigation phase, the decide/predict/action phases and the reflection phase. This approach is consistent with Kolb's model of experiential learning. The proof of concept model is of low sophistication but will be improved by the creative process described in the implementation plan (included below). The investigation (researching or exploration) phase is currently supported by a description of the current state, a series of strategically placed questions (that the student may ask), and relevant pictures, media and research links. In the decide/predict/action phases, students are required to select from prescribed actions after first predicting the likely outcome and explaining their rationale. If the selected action triggers a change of state the content will update for every student in every role of the scenario. Students will be prompted to reflect on the result of their action, or change of state, in their reflective journal.

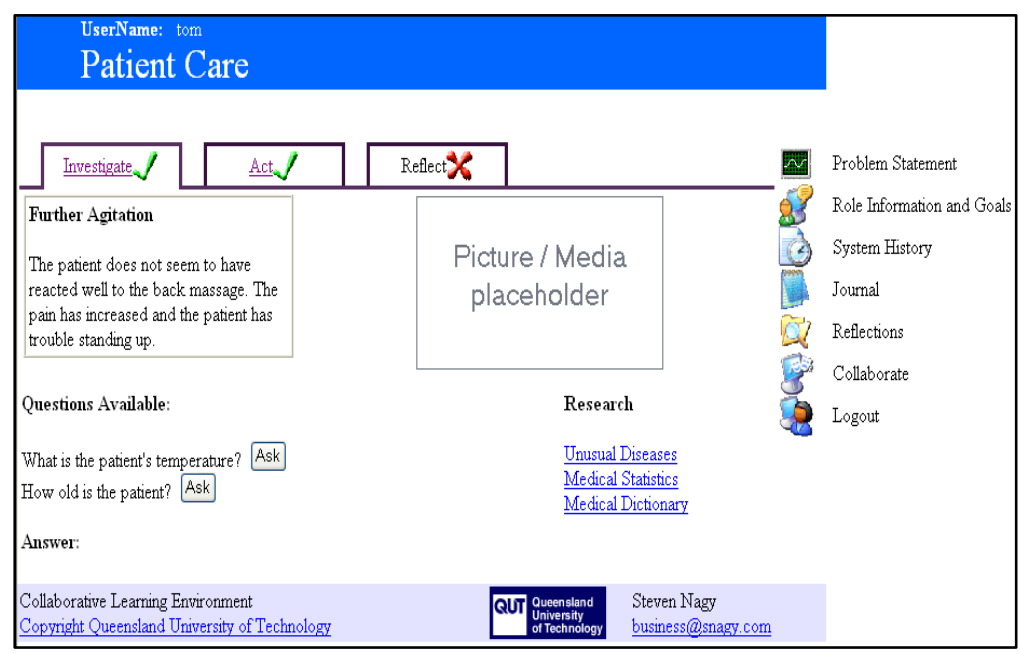

Figure 5: Proof of concept student interface 


\section{COPS project development}

A broad outline of the implementation plan for each stage of the COPS project is described in Table 1. To date COPS has completed most of the creativity and specification phases. Problem scenario definition work is underway. Preliminary paper-based trials of one of the potential problems have also been undertaken in 2006 and the results from that work are currently being analysed. We move into the building and remaining phases in early 2007 . At this stage the implementation issues of seven separate problem scenarios in seven units (a unit is single subject or course that runs for one semester) from four faculties at QUT are under consideration. These units are from the Faculties of Education, Information Technology, Health and Law. The paperbased trial has been done in the unit from Information Technology. These seven units will be culled to three units for actual piloting in 2007. COPS will be fully integrated with the existing online environment of each of the units identified for piloting.

Table 1: Broad outline of the development of COPS

Creativity Phase: In this phase the coordinators of the units selected for the pilot phase, QUT's learning designers, and relevant experts will establish the pedagogical goals of the Online Collaborative Problem Based Learning (online PBL) system and establish how the system can support face-to-face teaching, engagement and deep learning.

Specification phase and then build phase: This phase will create a specification for the system (both the student interface and the authoring interface). Upon signoff of this specification an alpha version of the online PBL system will be developed and user testing will be employed to facilitate development to beta stage. The system will be integrated with QUT's online learning management system. Academic staff will develop an approach to embed Collaborative Online Problem Based Scenarios into host units. These learning designs will then be implemented within the beta system.

Pilot phase: A pilot phase will determine the efficacy of the beta online PBL system (student side and author side) and the learning designs implemented. Each host unit will embed a PBL learning design, hosted through QUT's online learning management system, into the curricula. Evaluation data will be collected.

Refinement phase: Data from the pilot scheme will be evaluated to determine the efficacy of the system and the learning designs employed. The system, and the learning designs, will be refined in the light of these findings. The final version of the system and the reusable templates will then be delivered.

Dissemination phase: In the early stages of the pilot evaluation of data from student performance, both pre and post implementation will begin. Results from the student surveys and focus groups will be considered at the end of each stage, and compared with data emerging from standard formal evaluations of units. Usability analysis will be undertaken using tools such as Flashlight and other qualitative forms of analysis. The dissemination phase will include staff development sessions to facilitate other unit coordinators with using COPS.

To facilitate the creation of each of these problem scenarios, learning designers have developed a template (writing framework) to aid teaching staff in describing and planning their problem scenario, and to assist them in considering how they may incorporate their idea into a reality in their classrooms. This template also helps teaching staff with describing the details of their problem scenario in a style suitable for the purposes of the COPS project system designers. Teachers are initially asked to describe their proposed scenario within the case study to be completed by the student groups. They are then asked to define each of the group members' roles in the scenario. They are required to identify the issue/s, potential or otherwise, that need to be resolved by the group, or in the case of projects, the specific issues in relation to the tasks to be undertaken by each group member in their roles. They are expected to use this identification of issues to check how the tasks align with the outcomes and criteria they have already stated. 
Each teacher has been asked to describe the possible workflow pattern/s for the scenario's project teams. To do this they must consider how the activity or tasks of each role will influence the workflow pattern and its sequencing in terms of the group trying to resolve the problem tasks. In other words, by the time the teacher has described all of these segments, we have a simple description of what our COPS designers are going to need to ensure they have designed the environment to cope with these types of problems. It has already proved interesting, and often each scenario has some unique characteristics. For instance, some of the units require a scenario activity that will be completed within one tutorial or workshop alone, other units require the system to be capable of running for the duration of a semester, and other units fit anywhere along the semester time length continuum.

\section{Conclusion}

While many institutions are implementing online learning ostensibly to increase accessibility, flexibility, effectiveness (including cost-effectiveness), it is falling short of its promise to deliver on high quality outcomes for student engagement and learning. In order to redress this situation, and to focus on the pedagogical dimensions rather than the technical dimensions of learning, a community of researchers is exploring new authoring practices and tools which will support meaningful collaborative learning. This focus includes the creation and delivery of online activities that engage learners in constructing knowledge through experimenting, experiencing, forming assumptions, testing, and creating meaning from experience. This approach is in vivid contrast to the traditional didactic view of learners as passive recipients of knowledge (Chen, Chung, Crane, Hlavach, \& Viall, 2001; Jonassen, 1991; Savery \& Duffy, 1995).

\section{References}

Aronson, E., Blaney, N., Sikes, J., Stephan, C., \& Snapp, M. (1978). The jigsaw classroom. Beverly Hills, CA: Sage.

Bruffe, K. A. (1999). Collaborative learning: Higher education, interdependence, and the authority of knowledge. Baltimore, MD: John Hopkins University Press.

Bruner, J. (1973). Going beyond the information given. New York: Norton.

Caprio, M. W. (1994). Easing into constructivism, connecting meaningful learning with student experience. Journal of College Science Teaching, 23(4), 210-212.

Carr, S. (2001). Is anyone making money on distance education? The Chronicle of Higher Education, 47(23), 41-43.

Chen, P-L., Chung, D. S., Crane, A., Hlavach, L., \& Viall, E. (2001). Pedagogy under construction: Learning to teach collaboratively. Journalism and Mass Communication Educator, 56(2), 25-42.

CITI Seeding Grant and Teaching and Learning Small Grant. (2004). Developing a prototype collaborative problem based constructivist online learning environment: Project specification. Brisbane: Queensland University of Technology.

COPS - collaborative online problem solving learning environment. (2005-2007). Retrieved January 2, 2007, from http://olt.qut.edu.au/it/cops/

Dewey, J. (1938). Experience and education. New York: Macmillan.

Edens, K. M. (2000). Preparing problem solvers for the 21 st century through problem-based learning. College Teaching, 48(2), 55-60.

Harper, B. (2003). Web-based learning designs: Academic access to quality issues. Proceedings of the OLT Conference 2003, Brisbane. 
Herrington, J., Oliver, R., \& Reeves, T. C. (2003). Patterns of engagement in authentic online learning environments. Australian Journal of Educational Technology, 19(1), 59-71.

Holmboe, C., \& Scott, P. H. (2005). Characterising individual and social concept development in collaborative computer science classrooms. The Journal of Computers in Mathematics and Science Teaching, 24(1), 89.

Jonassen, D. H. (1991). Evaluating constructivist learning. Educational Technology, 31(9), 28 -33.

Jonassen, D. H. (1995). Constructivism and computer-mediated communication in distance education. American Journal of Distance Education, 9(2), 7-26.

Jonassen, D. H., Howland, J., Moore, J., \& Marra, R. M. (2003). Learning to solve problems with technology. Upper Saddle River, NJ: Merrill Prentice Hall.

Kagan, S. (1994). Cooperative learning. San Juan Capistrano: Resources for Teachers.

Kolb, D. A. (1984). Experiential learning: Experience as the source of learning and development. Englewood Cliffs: Prentice-Hall.

Laurillard, D. (2002). Rethinking university teaching: A conversational framework for the effective use of learning technologies. London: Routledge Falmer.

Major, C. H., \& Palmer, B. (2001). Assessing the effectiveness of problem based learning in higher education: Lessons from the literature. Academic Exchange Quarterly, 5(1), 4-8.

Nelson, L. M. (1999). Collaborative problem solving. In C. M. Reigeluth (Ed.), Instructional design theories and models: A new paradigm of instructional theory. Mahwah, NJ: Lawrence Erlbaum.

O’Neil, H., Chuang, S., \& Chung, G. (2003). Issues in computer based assessment of collaborative problem solving. Assessment in Education, 10(3), 361-373.

Oliver, R., \& Herrington, J. (2001). Teaching and learning online: A beginner's guide to e-learning and e-teaching in higher education. Perth: Edith Cowan University.

Phillips, J. M. (2005). Strategies for active learning in online continuing education. Journal of Continuing Education in Nursing, 36(2), 77-83.

Piaget, J., \& Inhelder, B. (1969). The psychology of the child. New York: Basic Books. [original work published 1966]

Qin, Z., Johnson, D., \& Johnson, J. (1995). Cooperative versus competitive efforts and problem solving. Review of Educational Research, 65(2), 129-143.

Ramsden, P. (1992). Learning to teach in higher education. London: Routledge.

Review of the University's online teaching activities. (2003). Brisbane: Queensland University of Technology. Retrieved (n.d.), from http://www.appu.qut.edu.au/committee/policyd/ reviewolt.doc

Rosenberg, M. J. (2001). E-learning: Strategies for delivering knowledge in the digital age. New York: McGraw-Hill.

Rust, C., O’Donovan, B., \& Price, M. (2005). A social constructivist assessment process model: How the research literature shows us this could be best practice. Assessment and Evaluation in Higher Education, 30(3), 231.

Savery, J. R., \& Duffy, T. M. (1995). Problem based learning: An instructional model and its constructivist framework. Educational Technology, 35(5), 31-38.

Schön, D. (1991). The reflective turn: Case studies in and on educational practice. New York: Teachers College Press.

Slavin, R. E. (1995a). Cooperative learning: Theory, research and practice. Boston: Allyn \& Bacon. 
Slavin, R, E. (1995b). Research on cooperative learning and achievement: What we know, what we need to know. Center for Research on the Education of Students Placed at Risk, Baltimore, MD: Johns Hopkins University.

Svetcov, D. (2000). The virtual classroom vs. the real one. Forbes, 166(7), 50-52.

Vrasidas, C. (2004). Issues of pedagogy and design in e-learning systems. Paper presented at the Symposium on Applied Computing, Nicosia, Cyprus.

Vygotsky, L. S. (1962). Thought and language. Cambridge, MA: M.I.T. Press.

Vygotsky, L. S. (1978). Mind in society: The development of higher psychological processes. Cambridge, MA: Harvard University Press.

Wankat, P. C., \& Oreovicz, D. S. (1993). Teaching engineering. New York: McGraw-Hill.

Wood, D. F. (2003). Problem based learning. British Medical Journal, 326(7384), 328-330.

Yam, S. C. (2004). Distance education and e-learning in the digital age: Critical considerations. In T. K. Shih \& P. P. Wang (Eds.), Intelligent virtual world: Technologies and applications in distributed world environments (pp. 289-308). Hackensack, NJ: World Scientific Publishers.

Zenger, J. \& Uehlein, C. (2001). Why blended will win. Training \& Development, 55(8), 54-60. Alexandria, VA: American Society of Training and Development.

\section{Acknowledgements}

The authors of this paper would like to acknowledge Dr Tony Sahama, Steven Nagy and the team from TALSS including Amanda Schnitzerling, Meredith Godat, Martin Perrett and Aneesha Bakharia.

Copyright $(2007$ Edwards, Watson, Farrell and Nash. 